\title{
Structure of the South Pole-Aitken Basin from KAGUYA Selenodesy Data
}

\author{
By Sho Sasaki ${ }^{1)}$, Yoshiaki Ishinara ${ }^{1)}$, Sander Goossens ${ }^{1,2)}$, Hiroshi Araki ${ }^{1)}$, Koji Matsumoto $^{1)}$, Hideo Hanada ${ }^{1)}$, \\ and Makiko OHтAке ${ }^{3)}$ \\ ${ }^{1)}$ RISE Project, National Astronomical Observatory of Japan, Oshu, Japan \\ ${ }^{2)}$ Goddard Space Flight Center/NASA, USA \\ ${ }^{3)}$ The Institute of Space and Astronautical Science, JAXA, Sagamihara, Japan
}

(Received June 27th, 2011)

\begin{abstract}
The South Pole-Aitken basin (SPA) is the largest (2500km in diameter), deepest and presumably oldest impact basin in the solar system. SPA was characterized by an ellipse with axes 2400 by $2050 \mathrm{~km}$, but more precise topography and gravity data are necessary to discuss the structure of large basin like SPA. We use localized representation of gravity potential where Slepian functions were used to estimate the gravity field over certain areas of the Moon and a spherical cap area with a radius of 40 degree from the SPA center. The direction of an ellipse denoting the depression is found to be similar to the previous result. The region with the thinnest crust is offset southward from the center of SPA. We analyzed interior structure of small basins in and around SPA. We interpret that a positive gravity anomaly corresponds to a Moho uplift. Just around the rim of SPA, a distinct Moho uplift beneath Schrödinger corresponds to the presence of olivine and obscure circular structure Amundsen-Ganswindt has a significant Moho uplift, suggesting a buried impact structure.
\end{abstract}

Key Words: Lunar Gravity, Crustal Thickness, South Pole Aitken Basin, Moho Uplift

\section{Introduction}

KAGUYA (SELENE) was launched on September 14th, 2007. From the end of October 2007, it started observation of the Moon form polar orbits and continued its operation by June 11th, 2009. KAGUYA had two subsatellites (OKINA and OUNA) for gravity measurements. Using 4-way Doppler tracking with relay satellite OKINA, KAGUYA obtained the first precise gravity field of the lunar farside ${ }^{1)}$. Multi-frequency differential (VLBI) observation of OKINA and OUNA improved the accuracy of gravity. From one-year tracking data, lunar gravity field model SGM100h was obtained $^{2)}$ and the model was refined into SGM100i taking into account VLBI data ${ }^{3)}$. KAGUYA has a laser altimeter (LALT) which measures the distance between the satellite and the lunar surface with accuracy of $1 \mathrm{~m}^{4}$. The gravity and topography data have been processed mainly at National Astronomical Observatory of Japan.

Bouguer gravity anomaly, Moho depth, and crustal thickness are obtained ${ }^{5)}$, using crustal density $2800 \mathrm{~kg} / \mathrm{m}^{3}$, mantle density $3360 \mathrm{~kg} / \mathrm{m}^{3}$, and mare basalt density 3200 $\mathrm{kg} / \mathrm{m}^{3}$. The crustal thickness was constrained assuming that the minimum thickness is not negative. The crustal thickness is nearly zero beneath Mare Moscoviense ${ }^{5)}$, which would have been formed by twice excavations by impacts and resulting a stronger Mohof uplift ${ }^{6}$. In the present study, we investigate the structure of South Pole-Aitken on the lunar farside using the first precise global lunar gravity and topography data obtained by KAGUYA mission.

\section{South Pole Aitken Basin}

The South Pole-Aitken basin (hereafter SPA) is the largest $(2500 \mathrm{~km}$ in diameter), deepest and presumably oldest impact basin in the solar system. It has a degraded morphology and abundant superimposed craters. On the basis of topography, Fe and Th abundance data, Garrick-Bethell and Zuber (2009) $\left(\right.$ GZ09 ${ }^{7)}$ showed that the SPA is characterized by an ellipse with axes 2400 by $2050 \mathrm{~km}$ with the center at 53S - 191E. More precise topography data (including polar region) and gravity data (including farside) are necessary to decipher the structure of large farside basin like SPA.

From the topography and the crustal thickness by KAGUYA, we confirmed that the direction of an ellipse denoting the depression is similar to that of GZ09. The region with the thinnest crust is offset southward from the center of SPA. In Fig. 1, Moho depth at the central region of SPA is around $30 \mathrm{~km}(25 \mathrm{~km}$ in crustal thickness $)$ and shallower to the southward. This may be explained by the oblique impact hypothesis advocated by GZ09.

Our crustal thickness is affected by the assumed anorthosite crustal density $2800 \mathrm{~kg} / \mathrm{m}^{3}$. KAGUYA MI showed evidence of anorthosite in SPA ${ }^{8)}$. But spectral data of central peaks of craters inside SPA show ultramafic assemblage dominated by magnesium rich orthopyroxene, suggesting the presence impact melt sheet ${ }^{9)}$. This is compatible with previous remote-sensing data ${ }^{10,11)}$. Then, higher crustal density would result in larger crustal thickness. The presence of lower crust in SPA was also discussed by previous gravity analysis ${ }^{12)}$. 


\section{Improvement of SPA Basin Gravity}

We use localized representation of gravity potential according to the Han (2008) ${ }^{13)}$ where Slepian functions were applied to estimate the gravity field over certain areas of the Moon. Using localized functions, we express the gravitational potential with localized spherical harmonics functions. We include data in a spherical cap area with a radius of 40 degree from the SPA center ${ }^{14)}$. This area is fully covered by 4 -way Doppler tracking of KAGUYA. We obtained gravity adjustment between plus and minus $68 \mathrm{mGal}$ with an (RMS) of $17 \mathrm{mGal}^{14}$ ). The improved gravity field would supply better data of crustal thickness with slightly higher resolutions.

\section{Small Basins Within and Around SPA}

SPA has overprinted by small impact basins, some of which are accompanied by gravity anomaly. We analyzed interior structure of small basins in and around SPA (Fig. 2 and Table 1) using newly estimated localized gravity model ${ }^{14)}$. We interpret that a positive gravity anomaly observed at some basins corresponds to change of crust-mantle boundary, i. e., a Moho uplift (a mantle plug).

There is a distinct gravity anomaly beneath Apollo (Fig. 3). This corresponds to thin crust with a large mantle plug. Just around the rim of SPA, obscure circular structure Amundsen-Ganswindt has a apparent Moho uplift, suggesting a buried impact structure (Fig. 3). Amundsen-Ganswindt is considered older than Schrödinger (Table 1) and probably buried by ejecta of impacts forming Schrödinger and other neighboring basins. A distinct Moho uplift beneath Schrödinger corresponds to the presence of olivine at the central peak rings there ${ }^{15)}$. In comparison between adjacent Poincaré and Planck basins of similar size, older, less distinct Poincaré shows stronger positive gravity anomaly suggesting a stronger Moho uplift. The observed anomaly beneath these basins corresponds to Type 2 like anomaly ${ }^{1)}$, where a significant uplift at basin center is probably due to overcompensation just after the impact. Probably thermo-mechanical properties of materials beneath Poincaré and Planck basins were different, or subsurface temperature under Planck was higher than that under Poincaré: later relaxation would have depressed or relaxed a Moho uplift beneath Planck.

Basin structures in the central SPA, on the other hand, show little gravity anomaly. Although it might be due to lower spatial resolution, there are several possibilities such as less density difference between crust and mantle and rapid relaxation of the uplift.

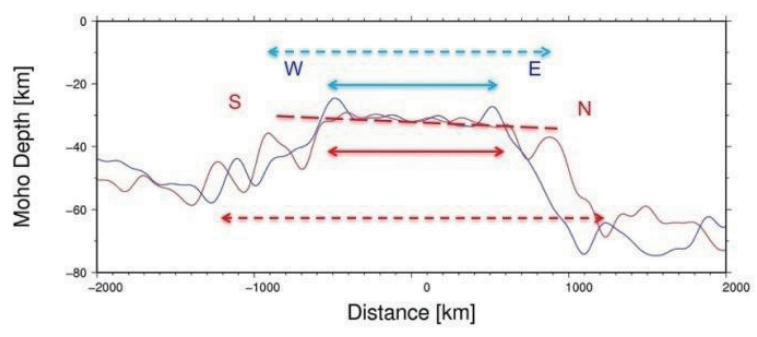

Fig. 1. Cross section of Moho depth of SPA.. Red curve and lines correspond to the long axis of ellipse by GZ09. Blue curve and lines correspond to the short axis by GZ09.

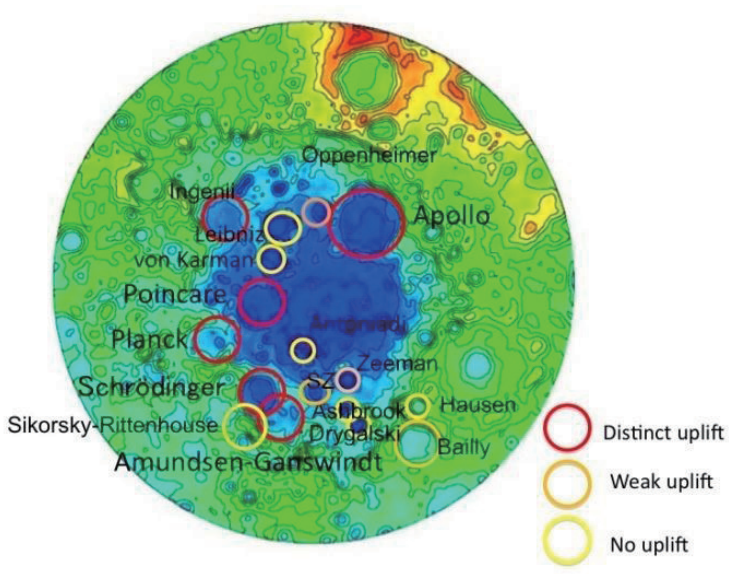

Fig. 2. Topography of the South Pole Aitken basin with overprinted impact basins which are investigated in this study.

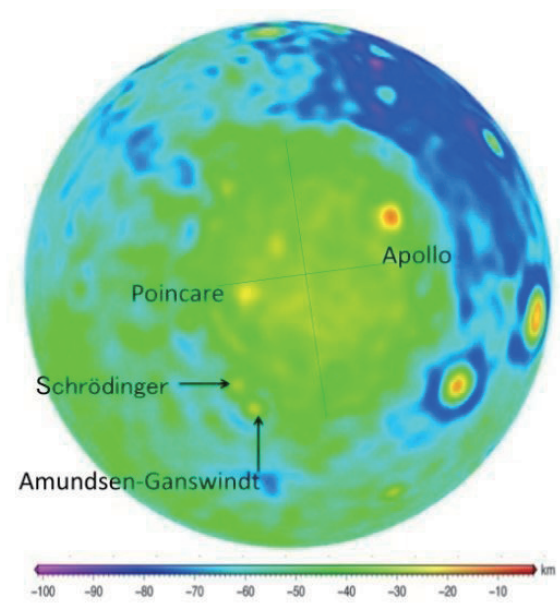

Fig. 3. Moho depth map of SPA region, indicating basins with distinct Moho uplift. Red and blue lines correspond to cross sections in Fig.1. 


\section{Acknowledgments}

We acknowledge KAGUYA team of JAXA for the operation of the successful mission. We thank an anonymous referee for the thoughtful review. This research was supported by a Grant-in-Aid for Scientific Research (A) (20244073, PI: S. Sasaki).

\section{References}

1) Namiki, N. et al.: Far side gravity field of the Moon from four-way Doppler measurements of SELENE (Kaguya), Science 323, (2009) pp.900-905.

2) Matsumoto K. et al.: An improved lunar gravity field model from SELENE and historical tracking data: revealing the farside gravity features, J. Geophys. Res. 115, (2010) E06007.

3) Goossens, S. et al.: Lunar gravity field determination using SELENE same-beam differential VLBI tracking data, J. Geodesy, 85 (2011) pp. 205-228.

4) Araki, H. et al. : Lunar global shape and polar topography derived from Kaguya-LALT laser altimetry, Science $\mathbf{3 2 3}$ (2009) pp.897-900.

5) Ishihara Y. et al.: Crustal thickness of the Moon: Implications for farside basin structures, Geophys. Res. Lett. 36, (2009) L19202.

6) Ishihara Y. et al.: Anomalous Moscoviense basin: single oblique impactor or double impact origin? Geophys. Res. Lett. 38, (2011) L03201.
7) Garrick-Bethell, I. and Zuber, M. T.: Elliptical structure of the lunar South Pole-Aitken basin, Icarus 204, (2009) pp.399-408.

8) Ohtake, M. et al.: The global distribution of pure anorthosite on the Moon, Nature 461, (2009) pp.237-241.

9) Nakamura, R. et al.: Ultramafic impact melt sheet beneath the South Pole-Aitken basin on the Moon, Geophys. Res. Lett. 36, (2009) L22202.

10) Head, J. W. et al.: Lunar impact basins: New data for the western limb and far side (Orientale and South Pole-Aitken Basins) from the first Galileo flyby, J. Geophys. Res. 98 (1993) pp.17149-17181.

11) Pieters, C. M. et al.: Rock types of the South Pole-Aitken basin and extent of basaltic volcanism, J. Geophys. Res. 106, (2001) pp.28001-28022.

12) Wieczorek, M. A., Phillips, R. J.: Lunar multiring basins and the cratering process, Icarus 139, (1999) pp.246-259.

13) Han, S.-C.: Improved regional gravity fields on the Moon from Lunar Prospector tracking data by means of localized spherical harmonic functions, J. Geophys. Res. 113, (2008) E11012.

14) Goossens, S. et al.: Local lunar gravity field analysis over the Souoth-Pole Aitken basin from SELENE farside tracking data, $J$. Geophys. Res. 117, (2012) E02005.

15) Yamamoto, S. et al.: Possible mantle origin of olivine around lunar impact basins, Nature Geoscience s, (2010) pp.533-536.

Table 1. Impact basins within and around SPA.

\begin{tabular}{|c|c|c|c|c|c|c|c|c|}
\hline & & & Diameter[km] & Clarity & Mare & $\begin{array}{l}\text { Moho } \\
\text { Uplift }\end{array}$ & $\begin{array}{l}\text { Crustal } \\
\text { Thickness }\end{array}$ & $\begin{array}{l}\text { Age (Wilhelms } \\
\text { age) }\end{array}$ \\
\hline Apollo & $36.1 \mathrm{~S}$ & $151.8 \mathrm{~W}$ & 538 & 0 & 0 & 0 & 7 & Pre-Nec(9) \\
\hline $\begin{array}{l}\text { Amundsen-Gan } \\
\text { swindt }\end{array}$ & $81 \mathrm{~S}$ & $120 \mathrm{E}$ & 335 & $x$ & $x$ & 0 & 26 & Pre-Nec(7) \\
\hline Poincaré & $56.7 \mathrm{~S}$ & $163.6 \mathrm{E}$ & 319 & 0 & 0 & O & 13 & Pre-Nec(4) \\
\hline Ingenii & $33.7 \mathrm{~S}$ & $163.5 \mathrm{E}$ & $315-660$ & 0 & O & $\mathrm{O}$ & 25 & Pre-Nec(4) \\
\hline Planck & $57.9 \mathrm{~S}$ & $136.8 \mathrm{E}$ & 314 & 0 & $x$ & o & 33 & Pre-Nec(7) \\
\hline Schrödinger & $75 \mathrm{~S}$ & $132.4 \mathrm{E}$ & 312 & 0 & 0 & o & 22 & $\operatorname{Imbrian}(12)$ \\
\hline $\begin{array}{l}\text { Sikorsky-Ritten } \\
\text { house }\end{array}$ & $68 \mathrm{~S}$ & $111 \mathrm{E}$ & 310 & $x$ & $x$ & $x$ & 48 & Nectarian $(11)$ \\
\hline Bailly & $66.5 \mathrm{~S}$ & $69.1 \mathrm{~W}$ & 300 & 0 & $x$ & $\Delta$ & 47 & Nectarian(11) \\
\hline $\begin{array}{l}\text { Schrödinger-Ze } \\
\text { eman }\end{array}$ & $81 \mathrm{~S}$ & $165 \mathrm{~W}$ & 250 & $x$ & $x$ & $\Delta$ & 28 & 12 \\
\hline Leibnitz & $38.3 \mathrm{~S}$ & $179.2 \mathrm{E}$ & 245 & 0 & 0 & $x$ & 25 & Pre-Nec \\
\hline Oppenheimer & $35.2 \mathrm{~S}$ & $166.3 \mathrm{~W}$ & 208 & 0 & 0 & $\Delta$ & 23 & \\
\hline Zeeman & $75.2 \mathrm{~S}$ & $133.6 \mathrm{~W}$ & 190 & 0 & $x$ & $\Delta$ & 31 & \\
\hline Von Kármán & $44.8 \mathrm{~S}$ & $175.9 \mathrm{E}$ & 180 & 0 & 0 & $x$ & 21 & Pre-Nec \\
\hline Hausen & $65.0 \mathrm{~S}$ & $88.1 \mathrm{~W}$ & 167 & 0 & $x$ & $x$ & 60 & \\
\hline Ashbrook & $81.4 \mathrm{~S}$ & $112.5 \mathrm{~W}$ & 156 & 0 & $x$ & $x$ & 39 & \\
\hline Drygalski & $79.3 \mathrm{~S}$ & $84.9 \mathrm{~W}$ & 149 & 0 & $x$ & $x$ & 45 & \\
\hline Antoniadi & $69.7 \mathrm{~S}$ & $172 \mathrm{~W}$ & 143 & 0 & 0 & $x$ & 25 & $\operatorname{Imbrian}(12)$ \\
\hline
\end{tabular}

